\title{
Screening for illicit drugs in pooled human urine and urinated soil samples and studies on the stability of urinary excretion products of cocaine, MDMA, and MDEA in wastewater by hyphenated mass spectrometry techniques
}

Mardal, Marie; Kinyua, Juliet; Ramin, Pedram; Miserez, Bram; van Nuijs, Alexander L. N.; Covaci, Adrian; Meyer, Markus R.

Published in:

Drug Testing and Analysis

Link to article, DOI:

10.1002/dta.1957

Publication date:

2017

Document Version

Publisher's PDF, also known as Version of record

Link back to DTU Orbit

Citation (APA):

Mardal, M., Kinyua, J., Ramin, P., Miserez, B., van Nuijs, A. L. N., Covaci, A., \& Meyer, M. R. (2017). Screening for illicit drugs in pooled human urine and urinated soil samples and studies on the stability of urinary excretion products of cocaine, MDMA, and MDEA in wastewater by hyphenated mass spectrometry techniques. Drug Testing and Analysis, 9(1), 106-114. https://doi.org/10.1002/dta.1957

\section{General rights}

Copyright and moral rights for the publications made accessible in the public portal are retained by the authors and/or other copyright owners and it is a condition of accessing publications that users recognise and abide by the legal requirements associated with these rights.

- Users may download and print one copy of any publication from the public portal for the purpose of private study or research.

- You may not further distribute the material or use it for any profit-making activity or commercial gain

- You may freely distribute the URL identifying the publication in the public portal 


\title{
Screening for illicit drugs in pooled human urine and urinated soil samples and studies on the stability of urinary excretion products of cocaine, MDMA, and MDEA in wastewater by hyphenated mass spectrometry techniques
}

\author{
Marie Mardal, ${ }^{a}$ Juliet Kinyua, ${ }^{b}$ Pedram Ramin, ${ }^{c}$ Bram Miserez, ${ }^{d}$ \\ Alexander L. N. van Nuijs, ${ }^{b}$ Adrian Covaci ${ }^{b}$ and Markus R. Meyer ${ }^{a, e_{*}}$
}

\begin{abstract}
Monitoring population drug use through wastewater-based epidemiology (WBE) is a useful method to quantitatively follow trends and estimate total drug consumption in communities. Concentrations of drug biomarkers might be low in wastewater due to dilution; and therefore analysis of pooled urine (PU) is useful to detect consumed drugs and identify targets of illicit drugs use. The aims of the study were (1) to screen PU and urinated soil (US) samples collected at festivals for illicit drug excretion products using hyphenated techniques; (2) to develop and validate a hydrophilic interaction liquid chromatography - mass spectrometry / mass spectrometry (HILIC-MS/MS) method of quantifying urinary targets of identified drugs in wastewater; and (3) to conduct a $24 \mathrm{~h}$ stability study, using PU and US to better reflect the chemical environment for targets in wastewater. Cocaine (COC) and ecstasy-like compounds were the most frequently detected illicit drugs; an analytical method was developed to quantify their excretion products. Hydroxymethoxymethamphetamine (HMMA), 3,4-methylenedioxymethamphetamine (MDMA), 3,4-methylenedioxyamphetamine (MDA), HMMA sulfate (HMMA-S), benzoylecgonine (BE), and cocaethylene (CE) had 85-102\% of initial concentration after $8 \mathrm{~h}$ of incubation, whereas COC and ecgonine methyl ester (EME) had 74 and $67 \%$ after $8 \mathrm{~h}$, respectively. HMMA showed a net increase during $24 \mathrm{~h}$ of incubation $(107 \% \pm 27, \mathrm{n}=8)$, possibly due to the cleavage of HMMA conjugates, and biotransformation of MDMA. The results suggest HMMA as analytical target for MDMA consumption in WBE, due to its stability in wastewater and its excretion as the main phase I metabolite of MDMA. Copyright $\odot 2016$ John Wiley \& Sons, Ltd.
\end{abstract}

Keywords: pooled urine analysis; illicit drugs; phase II metabolites; stability; wastewater-based epidemiology

\section{Introduction}

Analysis of wastewater for illicit drugs is a complementary approach to surveys for obtaining data on drug consumption trends in a community, since wastewater can be considered as a large, strongly diluted, pooled urine (PU) sample. ${ }^{[1-3]}$ Wastewater-based epidemiology (WBE) estimates drug consumption at the community level by quantifying excretion products (drug and/or its metabolites) in wastewater and back calculating concentration of these targets to actual drug consumption. An important prerequisite for these back calculations is the knowledge about the best biomarkers to reflect human consumption and their stability in the sewer. ${ }^{[4,5]}$

As illicit drugs can be extensively metabolized in humans, knowledge of their metabolism and stability of metabolites is of great interest. $^{[6]}$ Obtaining authentic urine samples with excretion products of illicit drugs can be challenging for ethical and legislative reasons. Pooled urine analysis (PUA) can overcome some of these issues and reveal the nature and type of drugs consumed by an investigated population. ${ }^{[7-10]}$ Furthermore, PUA offers realistic excretion patterns of illicit drugs and is easily accessible. Apart from PU, another way to collect urine is through urinated soil (US) samples. At events where people urinate in places other than lavatories and urinals, pools of urine and urinary metabolites can accumulate on the soil.

Stability data in wastewater are mainly available for drugs, but also for some metabolites. ${ }^{[4,5,11-13]}$ Gomes et al. tested the stability

\footnotetext{
* Correspondence to: Markus R. Meyer, Department of Clinical Pharmacology and Pharmacoepidemiology, Heidelberg University Hospital, Heidelberg, Germany. E-mail: markus.meyer@med.uni-heidelberg.de; markusr.meyer @gmx.de

a Department of Experimental and Clinical Toxicology, Institute of Experimental and Clinical Pharmacology and Toxicology, Saarland University, Homburg, Germany

b Toxicological Center, Department of Pharmaceutical Sciences, University of Antwerp, Antwerp, Belgium

c Department of Environmental Engineering, Technical University of Denmark, Kongens Lyngby, Denmark

d TICTAC Communications Ltd, St George's, University of London, London SW17 $O R E, U K$

e Department of Pharmacology and Pharmacoepidemiology, Heidelberg University Hospital, Heidelberg, Germany
} 
of estrogen phase II metabolites in wastewater and concluded that sulfates should have a high stability (above $80 \%$ ) after $8 \mathrm{~h}$ and glucuronides being below detection limit after $8 \mathrm{~h}$ of incubation. ${ }^{[14]}$ So far, only one study has investigated the stability of phase II metabolites of illicit drugs in wastewater. Glucuronides of 3,4methylenedioxypyrovalerone (MDPV) degraded in wastewater after $24 \mathrm{~h}$, whereas sulfates mostly remain intact. ${ }^{[4]}$ Currently used targets for cocaine (COC) and 3,4-methylenedioxymethamphetamine (MDMA) consumption in WBE are benzoylecgonine (BE) and MDMA itself, respectively. ${ }^{[15]}$ However, MDMA is known to be highly metabolized before being excreted into urine and hydroxymethoxymethamphetamine (HMMA) sulfates were found to be the most abundant products. ${ }^{[16]}$ Using MDMA itself as a target in WBE will not allow distinction between drug consumption and discharge.

Therefore, the aims of the present study were to collect PU and US samples from festivals and to screen these samples for excretion products of illicit drugs by mass spectrometry. Furthermore, an analytical method to quantify COC, MDMA 3,4-methylenedioxyethyleamphetamine (MDEA), and their main metabolites (Figure 1) in wastewater for stability studies was validated. Finally,
PU and US were incubated in wastewater and the stability of the investigated compounds, including their conjugates, was assessed over time.

\section{Experimental}

\section{Chemicals and reagents}

COC, COC- $d_{3}$, cocaethylene (CE), CE- $d_{3}, B E, B E-d_{3}$, MDEA- $d_{5}$, and HMMA were obtained by LGC standards, ecgonine methyl ester (EME) and EME- $d_{3}$ were obtained from Cerilliant (Round Rock, TX, USA). HMMA-d 3 , MDMA, MDMA-d ${ }_{5}, 3,4-$ methylenedioxymethamphetamine (MDA), and MDA- $d_{5}$ were obtained from Sigma-Aldrich (St Louis, MO, USA). HMMA sulfate (HMMA-S) was produced as described previously. ${ }^{[17]}$ Hydroxymethoxyethylamphetamine (HMEA) was produced as described previously. ${ }^{[18]}$ MDEA was obtained from seized materials. Dilutions and storage of $\mathrm{COC}$ and its metabolites were done in acetonitrile, for MDMA and metabolites in methanol. Isolute $\mathrm{C} 18(500 \mathrm{mg}, 3 \mathrm{~mL})$ and $\mathrm{HCX}$ cartridges $(130 \mathrm{mg}, 3 \mathrm{~mL})$ were obtained from Biotage (Uppsala, Sweden). Mixture (100<smiles>COC(=O)C1C2CCC(CC2)N1COC(=O)c1ccccc1</smiles>
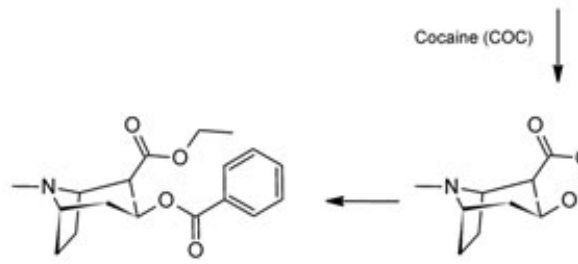

Cocaethylene(CE)

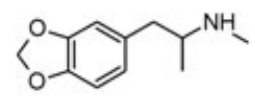

3.4-Methylenedioxymethamphetamine (MDMA)

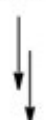<smiles>CNC(C)Cc1ccc(O)c(OC)c1</smiles>

Hydroxymethoxymethamphetamine (HMMA)

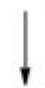<smiles>CNC(C)Cc1ccc(OS(=O)(=O)O)c(OC)c1</smiles>

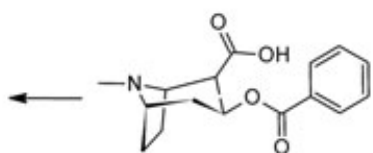

Benzoylecgonine (BE)

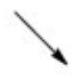<smiles>COC(=O)C1C(O)CC2CCC1N2C</smiles>

Ecgonine Methyl Ester (EME)<smiles>CCNC(C)Cc1ccc2c(c1)OCO2</smiles>

3.4-Methylenedioxyethylamphetamine (MOEA)

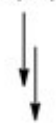<smiles>CCNC(C)Cc1ccc(O)c(OC)c1</smiles>

Hydroxymethoxymethamphetamine sulfate (HMMA-S)

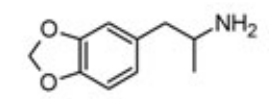

3,4-Methylenedioxyamphetamine (MDA)

Figure 1. Chemical structures of the investigated excretion products. Arrows indicate metabolic pathways. 
$000 \mathrm{U} / \mathrm{mL}$ ) of glucuronidase (EC No. 3.2.1.31) and arylsulfatase (EC No. 3.1.6.1) from $H$. Pomatia and analytical grade ammonium acetate from Merck (Darmstadt, Germany). All other chemicals and reagents (analytical grade), and centrifugal filters were from VWR (Darmstadt, Germany). The P-Tree Urinal was from Aandeboom (Utrecht, the Netherlands).

\section{Collection of pooled urine samples and urinated soil samples}

All samples were collected at two European music festivals in 2014. PU samples were collected by two different methods:

A. Extracted from tulip urinals (individually collected PU samples, $n=11$ ) using a plastic hose and plastic syringe, collected from three independent urinals at different time points over three days.

B. Collected from urinals (Pee tree urinals, $n=10$ ) mounted on a wall, connected to a $30 \mathrm{~L}$ container located in a protected environment.

All PU samples were spiked on site with $\mathrm{HMMA}-\mathrm{d}_{3}$ to a final concentration of $100 \mathrm{ng} / \mathrm{mL}$ and stored in polystyrene containers and immediately put on ice until freezing ( $\max 12 \mathrm{~h}$ ).

US was collected from areas (fences, bushes, etc.) where pools of urine were visible on the surface. The characteristics (liquid content, colour, type of soil) differed from urine with small amounts of sand to humus with high organic content.

\section{Sample preparation and screening analysis of urine samples and urinated soil samples}

An overview of sample preparation of PU and US is presented in Figure 2. Sample preparation for PU was according to previously published standard urine sample protocols, to identify excretion products (parent drug and metabolites) of illicit and therapeutic drugs. ${ }^{[19]}$ Briefly, Phase I metabolites were identified after enzymatic cleavage of conjugates in $1 \mathrm{~mL}$ PU added internal standard $\left(1 \mu \mathrm{g} / \mathrm{mL}\right.$ trimipramin- $\left.d_{3}\right)$; basic and neutral/acidic phase I metabolites were then separated by applying the cleaved PU onto HCX cartridges and dividing each fraction into two. One fraction was acetylated and injected onto gas chromatography-mass spectrometry (GC-MS) using a Hewlett Packard (HP, Waldbronn, Germany) 5890 Series II gas chromatograph system. The other part was analyzed by liquid chromatography-high resolution-tandem mass spectrometry (LC-HR-MS/MS) using a Thermo Fisher $\mathrm{Q}$ Exactive and LC-ion trap mass spectrometry (LC-MS $\left.{ }^{n}\right)$ using a Thermo Fisher LXQ both coupled to Accela LC systems. Phase II metabolites were identified after extracting $1 \mathrm{~mL}$ PU added internal standard $(1 \mu \mathrm{g} /$ $\mathrm{mL}$ trimipramin- $\mathrm{d}_{3}$ ) on $\mathrm{C} 18$ cartridges and after precipitation of $100 \mu \mathrm{L}$ PU with $500 \mu \mathrm{L}$ acetonitrile, then analyzed using LC-HRMS/MS and LC-MS ${ }^{n}$ mentioned above (Figure 2). ${ }^{[20,21]}$ Acquired LC-HR-MS/MS data were analyzed for common new psychoactive substances (NPS) and metabolites, by extracting ion chromatograms from full scan, as well as mining MS spectra in datadependent mode. ${ }^{[20]}$

Sample preparation for US was as follows: $0.5 \mathrm{~g}$ of US was mixed with $0.5 \mathrm{~mL}$ acetonitrile with internal standard $(100 \mathrm{ng} / \mathrm{mL}$ HMMA$d_{3}$ ). This mixture was thoroughly vortexed and centrifuged for $5 \mathrm{~min}$ at $18,407 \mathrm{~g}$ and $10 \mu \mathrm{L}$ were injected onto the LC-HR-MS/MS and LC-MS ${ }^{n}$ systems as used for the PU samples, with instrument settings as previously reported for standard human urine samples. ${ }^{[19-21]}$

\section{Collection of wastewater samples}

Wastewater was collected for the stability assessment of urinary targets on a dry day as a $24 \mathrm{~h}$ time-proportional composite sample from a wastewater treatment plant in Wulpen, Belgium.

\section{Instrumentation for wastewater incubations}

The LC system consisted of an Agilent 1200 series High Pressure LC fitted with a degasser, a binary high-pressure gradient pump, a heated column compartment and an autosampler module without cooling. Chromatographic separation was achieved using a Phenomenex LUNA HILIC $200 \AA$ ( $150 \times 3$ mm, $5 \mu \mathrm{m})$ column, with a mobile phase composed of A) $5 \mathrm{mM}$ ammonium acetate in ultrapure water and B) acetonitrile, at a flow rate of $0.4 \mathrm{~mL} / \mathrm{min}$. The gradient was as follows: 0-0.5 min 95\% B, 0.5-6.5: 60\% B, 6.5-9 min: $52 \%$ B, 9-9.5 min: $95 \%$ B. The total runtime, including column

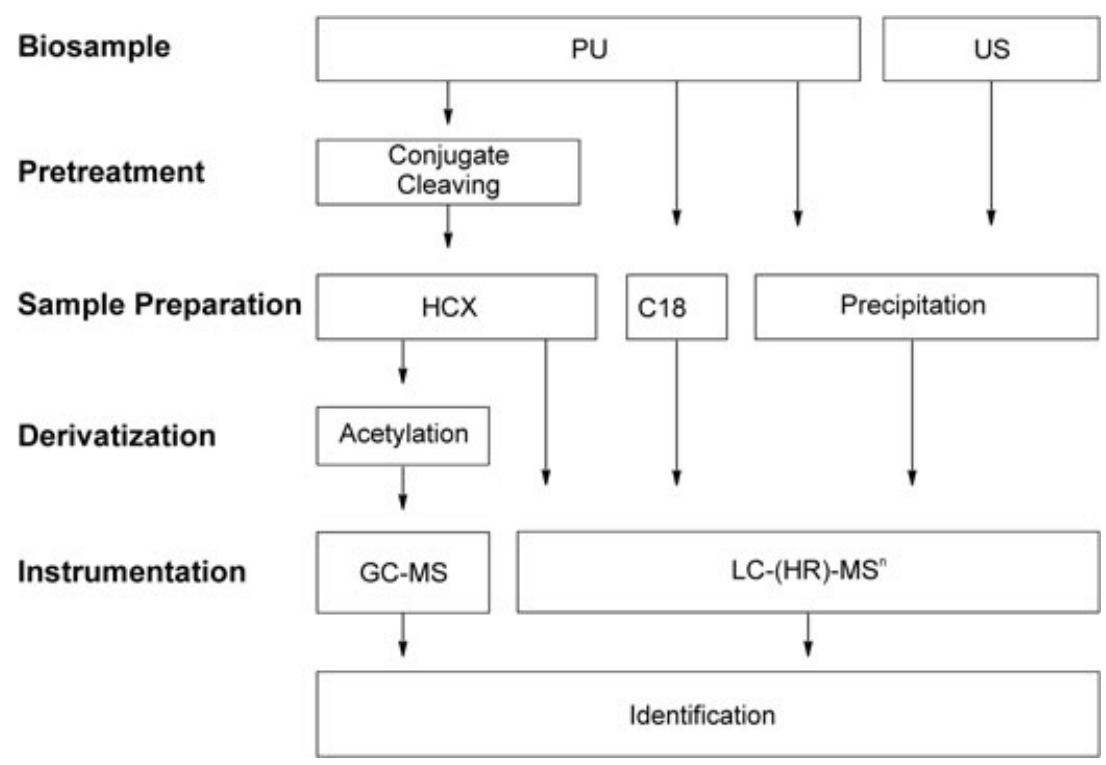

Figure 2. Overview of instrumentation and sample preparation methods for screening pooled urine and urinated soil samples for illicit drugs and therapeutic drugs. 
equilibration, was $15.5 \mathrm{~min}$. All compounds were eluted within $8 \mathrm{~min}$. The injection volume was set to $2 \mu \mathrm{L}$. The LC system was coupled to an Agilent 6410 triple quadrupole mass spectrometer with an electrospray interface (ESI) for detection and quantification of the compounds. Source parameters were as follows: gas temperature of $350^{\circ} \mathrm{C}$, gas flow $12 \mathrm{~L} / \mathrm{min}$, nebulizer 40 psi, capillary voltage $+4000 \mathrm{~V}$ and delta EMV 450, time frame was set to $0.15 \mathrm{~min}$. The mass spectrometer compound dependent parameters were optimized for each compound individually (Table 1) by direct injection (without analytical column) of standards using MassHunter Optimizer (v. B 03.01) Source parameters (gas temperature, gas flow, nebulizer pressure, and capillary voltage) were optimized to acquire an intense protonated molecular species $[\mathrm{M}+\mathrm{H}]^{+}$for each compound. Mass spectrometer compound dependent parameters, fragmentor voltage, and collision energy were optimized to acquire two multiple reaction monitoring (MRM) transitions (qualifier and quantifier) for each compound, including internal standards. The most abundant transition was chosen as quantifier (Q) and the second most abundant transition as qualifier (q). The Q/q ratio was monitored for variation (RSD 20\%) to provide an additional identification criterion besides the retention time. For LC optimization, a mix of standards with all compounds was injected on three different HILIC columns for evaluation of separation power. In addition, different injection volumes $(1,2,3$, and $5 \mu \mathrm{L})$ were tested, and optimized based on effect on peak shape.

\section{Method validation for analysis of wastewater incubations}

Method validation was based on the EMA guidelines on bioanalytical method validation with some exceptions. ${ }^{[22]}$ Precision, accuracy, linearity, selectivity, calibration range, lower limit of quantification (LLOQ) and sensitivity were tested. Multi-component calibration curves were established in wastewater with a minimum of six calibration points, by spiking stock solution into previously collected grab samples wastewater, then mixing $50 \mu \mathrm{L}$ spiked wastewater with $50 \mu \mathrm{L}$ internal standard in acetonitrile, filtering samples through $0.45 \mu \mathrm{m}$ nylon membrane filter units and centrifuging them for $5 \mathrm{~min}$ at $18000 \mathrm{~g}$. Signals from each analyte were corrected for their corresponding deuterated internal standard (IS), with the exceptions of HMMA and HMMA-S, where MDMA- $d_{5}$ was used as internal standard. IS was prepared by diluting stock solutions in acetonitrile to a final concentration in prepared sample of $84 \mathrm{ng} / \mathrm{mL}$ for COC- $d_{3}, C E-d_{3}$, and MDMA- $d_{5}, 40 \mathrm{ng} / \mathrm{mL}$ for EME- $d_{3}$ and $B E-d_{3}$, and $140 \mathrm{ng} / \mathrm{mL}$ for MDA- $d_{5}$ and MDEA- $d_{5}$.

A blank sample (wastewater sample with acetonitrile) and a zero sample (wastewater sample with IS) were run together with the calibration curves. The medium quality control $\left(\mathrm{QC}_{\text {med }}\right)$ was prepared for the method validation, and additionally two quality controls, one low $\left(\mathrm{QC}_{\text {low }}\right)$ and one high ( $\left(\mathrm{QC}_{\text {high }}\right)$ were added for the analytical runs. QCs were prepared in the same way as calibration points and used to calculate accuracy and precision. Calibration curves for quantification were constructed in Agilent MassHunter Quantitative Browser by plotting peak areas of the analytes divided by the corresponding internal standard, against the spiked concentration and weighted by $1 / x$. Carryover was tested by injecting the blank after the highest calibrator and repeated three times.

Intra- and inter-day accuracy and precision were based on calculating concentrations of quality control samples from established calibration curves, using $\mathrm{QC}_{\text {med }}(\mathrm{n}=6)$ for intra-day and all three QCs ( $n=6-13)$ for inter-day accuracy and precision. The results were assessed with an acceptance criterion within 85-115\% (mean) accuracy and $<15 \%$ precision, as confidence value (CV). LLOQ was based on visual inspection, and complied with EMA guidelines on $\pm 20 \%$ back-calculated concentrations.

\section{Stability assessment of urinary targets in wastewater}

The workflow for the multi-step preparation of the incubations is presented in Figure 3. Screening analysis provided estimations on which PU and US samples had high and low concentrations of COC, MDMA, and MDEA excretion products, respectively. These estimations were used to design wastewater incubations with high, low, or medium concentrations of COC, MDMA, and MDEA excretion products. A blank incubation was run to correct for possible

Table 1. Optimized MRM transitions and retention times for selected compounds and the deuterated internal standards.

\begin{tabular}{|c|c|c|c|c|c|c|}
\hline Compound Name & $\begin{array}{l}\text { Retention } \\
\text { time, min }\end{array}$ & $\begin{array}{l}\text { Precursor } \\
\text { ion, } m / z\end{array}$ & $\begin{array}{c}\text { Fragmentor } \\
\text { voltage, V }\end{array}$ & $\begin{array}{l}\text { Collision } \\
\text { energy, V }\end{array}$ & $\begin{array}{c}\text { Quantifier } \\
\text { Product } \\
\text { ion, } m / z\end{array}$ & $\begin{array}{c}\text { Qualifier } \\
\text { Product } \\
\text { ion, } m / z\end{array}$ \\
\hline Benzoylecgonine & 5.3 & 290.1 & 124 & 14 & 168.1 & 105.1 \\
\hline Benzoylecgonine- $d_{3}$ & 5.3 & 293.2 & 122 & 13 & 171.1 & 105.0 \\
\hline Cocaethylene & 5.8 & 318.2 & 134 & 14 & 196.1 & 82.1 \\
\hline Cocaethylene- $d_{3}$ & 5.9 & 321.2 & 132 & 16 & 199.1 & 85.1 \\
\hline Cocaine & 5.4 & 304.2 & 124 & 14 & 182.1 & 82.1 \\
\hline Cocaine- $d_{3}$ & 5.6 & 307.1 & 124 & 14 & 185.1 & 85.1 \\
\hline Ecgonine Methyl Ester & 7.5 & 200.2 & 124 & 14 & 182.1 & 82.1 \\
\hline Ecgonine Methyl Ester- $d_{3}$ & 7.6 & 203.2 & 118 & 14 & 185.1 & 85.1 \\
\hline HMEA & 7.4 & 210.1 & 89 & 4 & 165.1 & 137.1 \\
\hline HMMA-S & 4.1 & 276.0 & 105 & 12 & 165.1 & 137.1 \\
\hline HMMA & 7.7 & 196.1 & 88 & 8 & 165.1 & 137.1 \\
\hline MDA & 7.4 & 180.2 & 80 & 4 & 163.1 & 105.1 \\
\hline MDA-d $d_{5}$ & 7.5 & 185.2 & 80 & 4 & 168.1 & 110.1 \\
\hline MDEA & 7.1 & 208.2 & 88 & 9 & 163.0 & 105.1 \\
\hline MDEA-d ${ }_{5}$ & 7.1 & 213.1 & 92 & 8 & 163.1 & 105.1 \\
\hline MDMA & 7.3 & 194.1 & 92 & 9 & 163.0 & 105.1 \\
\hline MDMA-d ${ }_{5}$ & 7.3 & 199.1 & 92 & 21 & 163.1 & 107.1 \\
\hline
\end{tabular}




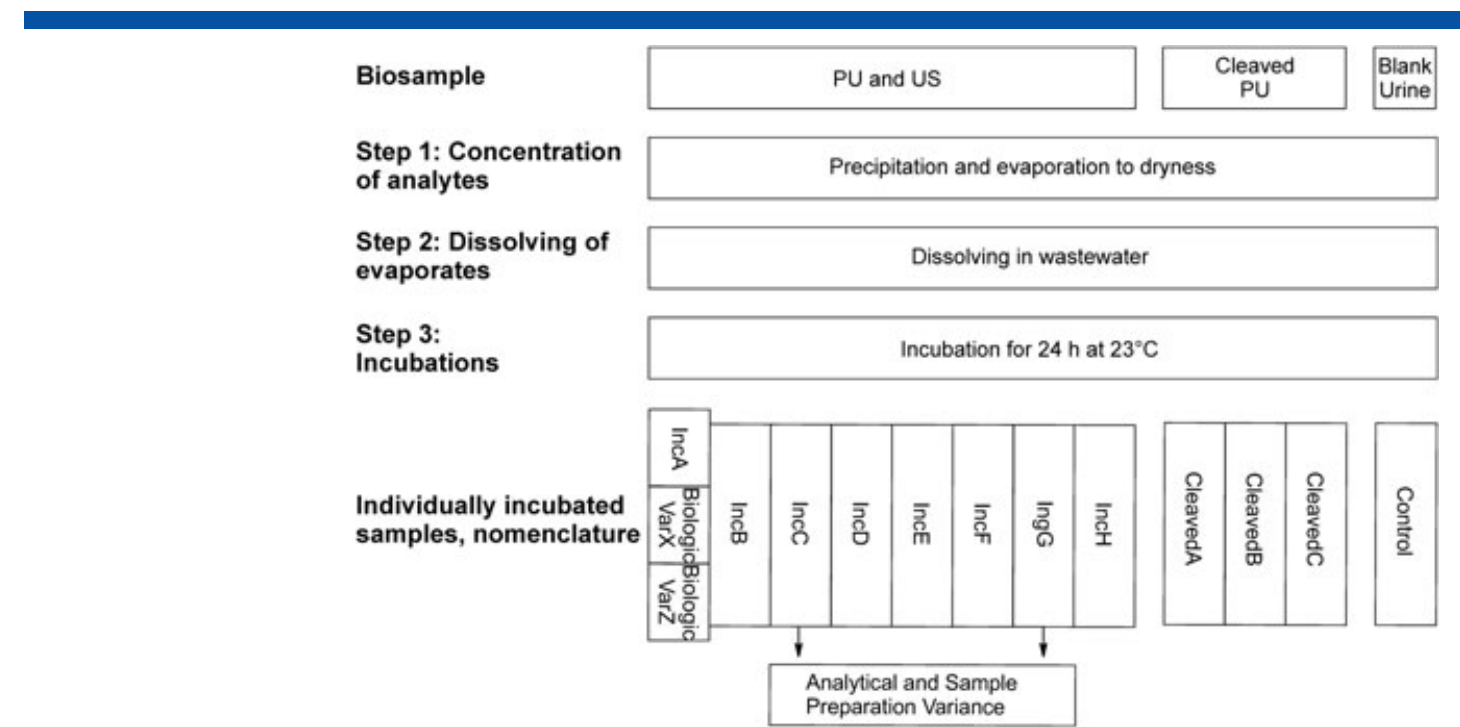

Figure 3. Overview of incubation workflow, which samples are used to assess biological, analytic and sample preparation variance, and nomenclature for samples. Biosample: PU, US, cleaved PU, or blank urine

back-ground excretion products present in wastewater. Only PU and US with COC, MDMA, and/or MDEA excretion products were used for stability assessment of urinary targets in wastewater. To investigate stability of phase I metabolites and parent drug with minimal interference from phase II metabolites, three wastewater incubations were prepared with conjugate cleaved PU (Figure 3), from PU samples tested positive for COC and MDMA excretion products in the screening analysis. Three PU samples were enzymatically cleaved by adjusting them to $\mathrm{pH}$ to $5.2 \pm 0.1$ with $0.1 \mathrm{M}$ $\mathrm{HCl}$ and $0.1 \mathrm{M} \mathrm{NaOH}$, then adding $50 \mu \mathrm{L}$ glucuronidase/ arylsulfatase, and incubating the mix for $30 \mathrm{~min}$ at $70^{\circ} \mathrm{C}$ in a GC oven.

\section{Step 1: Concentration of analytes}

All samples were concentrated by precipitation with methanol and evaporation to dryness. Five $\mathrm{mL}$ PU, US, cleaved urine, or blank urine were mixed with ice cold methanol (50:50 v/v \%) and centrifuged for $10 \mathrm{~min}$ at $2000 \mathrm{~g}$. The supernatants were evaporated to dryness at $40^{\circ} \mathrm{C}$ under a gentle stream of nitrogen.

Step 2: Dissolving in wastewater

The concentrated PU, US, cleaved urine, or blank urine was diluted in wastewater to fit the calibrated range. A total volume of $4 \mathrm{~mL}$ of each incubation was transferred to $50 \mathrm{~mL}$ falcon tubes.

Step 3: Incubations

All samples were incubated at $23^{\circ} \mathrm{C}$ in a temperate water bath for $24 \mathrm{~h}$. Sampling of each incubation was made after $0,0.5,1,2,3,5$, 8,12 , and $24 \mathrm{~h}$.

One of the incubations (IncA) was divided into three separate containers to assess biological variance (IncA, BioVarX, BioVarZ), i.e., the variance introduced by different transformation from the biological communities in wastewater. Incubation $\mathrm{pH}$ was monitored with indicator paper.

\section{Sample preparation of wastewater incubations}

An aliquot of $50 \mu \mathrm{L}$ from the wastewater incubations was mixed with $50 \mu \mathrm{L}$ internal standard in acetonitrile and samples were filtered through $0.45 \mu \mathrm{m}$ nylon membrane filter units that were centrifuged for $5 \mathrm{~min}$ at $18000 \mathrm{~g}$.

\section{Evaluation of analytical data for stability studies}

Variance introduced post-injection (analytical variance), from the sample preparation (sample preparation variance) and from variance introduced by different transformation from the biological communities in wastewater (biological variances) were assessed for MDMA and COC excretion products in real samples. Biological variance was assessed after 3, 12, and $24 \mathrm{~h}$. Analytical and sample preparation variances were tested using IncC and IncG from a single time point, respectively. Both samples were prepared five times (sample preparation variance) and one of these was injected five times (analytical variance). F-tests were calculated using Microsoft Excel 2007 add-in program, Analysis ToolPak F-test.

Compound stability compared to initial concentration was classified using slightly modified definitions presented by McCall et al. ${ }^{[23]}$ A compound had a high stability when more than $80 \%$ of the original concentration remained after defined time period, medium stability when $40-80 \%$ remained, and a low stability when less than $40 \%$ remained. Stability was assessed after 8 and $24 \mathrm{~h}$.

\section{Results and discussion}

\section{Screening of pooled urine samples and urinated soil samples}

Two different analytical systems (GC and LC) have been used to cover a wide range of analytes. The methods used are expected to be comprehensive to each other and were therefore used to screen for therapeutic drugs as well as for drugs of abuse originating from different drug classes. COC and MDMA were the most frequently detected illicit drugs in the investigated PU and US samples (Table 2). Other identified illicit drugs were MDEA, MDA, methamphetamine, amphetamine, ketamine, and sildenafil. All compounds except amphetamine were also identified by metabolites. It should be noted, that the latter two are also therapeutic drugs, but have potential for non-prescription abuse. MDA is the main excretion product after MDA use, but is also an excretion product of MDMA and MDEA. ${ }^{[18,24,25]}$ Signal intensities of MDA in the PU and US 
Table 2. Frequency of detected illicit drugs by GC-MS and LC-(HR)-MS ${ }^{n}$ M: metabolites.

\begin{tabular}{|lccc|} 
& Tulip Urinals & PeeTree Urinals & $\begin{array}{c}\text { Urinated Soil } \\
\text { Samples } \\
\mathrm{n}=12\end{array}$ \\
\hline Cocaine $+\mathrm{M}$ & 10 & $\mathrm{n}=10$ & 8 \\
MDMA + M & 9 & 1 & 8 \\
Ketamine $+\mathrm{M}$ & & & 1 \\
Sildenafil $+\mathrm{M}$ & 3 & 1 & 1 \\
Amphetamine & 3 & & \\
MDEA + M & 2 & & \\
\hline
\end{tabular}

samples were lower than MDMA and MDEA signal intensities, it is thus assumed to be present as a metabolite of the latter two. The US samples were found to be a useful addition to the PU samples. No standard urine screening approaches for illicit drug excretion products on US were found in the literature. Further studies should investigate additional sample preparation methods, including conjugate cleavage. ${ }^{[26]}$ Ketamine and sildenafil metabolites were only detected in the US samples. Ketamine might also originate from other sources than human consumption, such as excretion of veterinarian medicine. However, ketamine is mainly abused by people and used only for veterinarian purposes of large animals. Frequencies of detected illicit drugs are summarized in Table 2. This high prevalence of COC and MDMA was also seen in PU samples collected from the center of London by Archer et al. ${ }^{[10]}$ However, no NPS could be detected in our study. This might be explained most likely by absence of consumption or levels below limit of detection. In the future, more sensitive and targeted screening strategies may overcome such limitations in part. ${ }^{[27]}$ Based on the findings from the screening, MDMA, COC, and MDEA were chosen as substances to test stability of main urinary excretion products in wastewater.

\section{Analytical method for wastewater incubations}

As expected, based on previous studies, ${ }^{[28]}$ HILIC separation of the compounds of interest was sufficient and robust. HILIC was chosen as it should be suitable for polar analytes, such as metabolites, and should increase separation power compared to reverse phase columns for these types of compounds due to the different solid phases. For the current method, performance was optimized for method application to stability studies with high concentrations and simple sample preparation. The range for MDMA and BE were designed higher than other analytes (Table 3), as the PU and US screening showed that these two compounds were present in high concentrations in the PU and US samples. A reconstructed ion chromatogram of quantifier transitions of $\mathrm{Q} C_{\text {med }}$ for MDMA and $B E$ and $Q C_{\text {high }}$ for the remaining analytes is presented in Figure 4. The peak of HMMA-S was tailing but precision and accuracy were within \pm 7 $\%$ and $95-107 \%$, respectively. Selectivity, linearity, LLOQ, precision, accuracy, and carry-over were assessed for the method validation. All tested parameters were within the ranges defined by the EMA. A summary of the validation data can be found in Table 3 .

The LLOQ of the compounds ranged from 2.7 to $20.6 \mathrm{ng} / \mathrm{mL}$ and the upper limit of quantification from 340.2 to $2574.6 \mathrm{ng} / \mathrm{mL}$ with a minimum of six calibration points. All calibration curves had a squared correlation coefficient higher than 0.99 using $1 / x$ weighing. MDMA- $d_{5}$ was used as internal standard for HMMA and HMMA-S.

The back-calculated concentration of all calibration points were within $\pm 15 \%$ and $\pm 20 \%$ for the LLOQ.

Precision and accuracy were tested inter- and intra-day using $\mathrm{QC}_{\text {med. }}$. Additionally, two QC levels were used in the analytical runs as autosampler stability was not assessed. Accuracy ranged from 93 to $106 \%$ and precision (as CV at confidence level 0.05 ) from $1 \%$ to $10 \%$.

Matrix effects were not investigated as all incubations, $Q C_{\text {high }}$ and $\mathrm{QC}_{\text {low }}$ were made from the same batch of wastewater. Recovery was not tested as it is no longer recommended in the latest EMA guidelines. Sample preparation consisted of dilution and all QCs were within limits for accuracy and precision. ${ }^{[22]}$ Neither investigated excretion products nor interfering compounds could be detected in any blank samples.

\section{Stability of urinary metabolites in wastewater}

The validated method was used to investigate the stability of the excretion products from the PU and US samples spiked in wastewater. Incubations were designed to give a large initial variance in absolute concentration of COC and MDMA excretion products, based

Table 3. Method validation data: Linear range in $\mathrm{ng} / \mathrm{mL}$, number of calibration points for the calibration curve $\left(\mathrm{R}^{2}>0.99\right.$ for all calibration curves), accuracy in \%, precision in confidence value at $\alpha=0.05$, inter-day at 1 concentration level, intra-day at 3 concentration levels.

\begin{tabular}{|c|c|c|c|c|c|c|c|c|c|c|}
\hline & \multirow{3}{*}{$\begin{array}{l}\text { Linear } \\
\text { range, ng/ } \\
\mathrm{mL}\end{array}$} & \multirow{3}{*}{$\begin{array}{l}\text { Calibration } \\
\text { points }\end{array}$} & \multicolumn{4}{|c|}{ Accuracy, \% } & \multicolumn{4}{|c|}{ Precision, \% } \\
\hline & & & \multicolumn{2}{|l|}{ Inter-day } & \multicolumn{2}{|l|}{ Intra-day } & \multicolumn{2}{|l|}{ Inter-day } & \multicolumn{2}{|l|}{ Intra-day } \\
\hline & & & $\begin{array}{c}\mathrm{QC}_{\text {med }} \\
\mathrm{n}=6\end{array}$ & $\begin{array}{c}\mathrm{QC}_{\text {low }} \\
\mathrm{n}=6\end{array}$ & $\begin{array}{l}\mathrm{Q} C_{\text {med }} \\
\mathrm{n}=13\end{array}$ & $\begin{array}{c}Q C_{\text {high }} \\
n=6\end{array}$ & $\begin{array}{c}\mathrm{Q} C_{\text {med }} \\
\mathrm{n}=6\end{array}$ & $\begin{array}{l}\mathrm{QC}_{\text {low }} \\
\mathrm{n}=6\end{array}$ & $\begin{array}{l}\mathrm{Q} C_{\text {med }} \\
\mathrm{n}=13\end{array}$ & $\begin{array}{c}\mathrm{QC}_{\text {high }} \\
\mathrm{n}=6\end{array}$ \\
\hline Benzoylecgonine & $10.3-2574.6$ & 9 & 102 & 94 & 95 & 97 & 1 & 4 & 4 & 3 \\
\hline Cocaethylene & $2.7-340.2$ & 8 & 95 & 97 & 96 & 98 & 3 & 2 & 3 & 3 \\
\hline Cocaine & $5.4-340.2$ & 7 & 93 & 100 & 99 & 101 & 2 & 3 & 3 & 3 \\
\hline Ecgonine Methyl Ester & $8.2-340.2$ & 6 & 98 & 100 & 100 & 100 & 5 & 9 & 5 & 3 \\
\hline HMEA & $5.4-340.2$ & 7 & 103 & 95 & 96 & 96 & 2 & 8 & 4 & 5 \\
\hline HMMA-S & $9.6-340.2$ & 7 & 95 & 106 & 101 & 107 & 4 & 7 & 4 & 6 \\
\hline HMMA & $2.7-340.2$ & 8 & 100 & 94 & 94 & 99 & 3 & 6 & 6 & 5 \\
\hline MDA & $8.2-340.2$ & 6 & 97 & 99 & 100 & 100 & 2 & 5 & 3 & 2 \\
\hline MDEA & $5.4-340.2$ & 7 & 97 & 99 & 97 & 98 & 4 & 5 & 4 & 3 \\
\hline MDMA & $20.6-2574.6$ & 8 & 96 & 99 & 98 & 98 & 3 & 10 & 4 & 10 \\
\hline
\end{tabular}




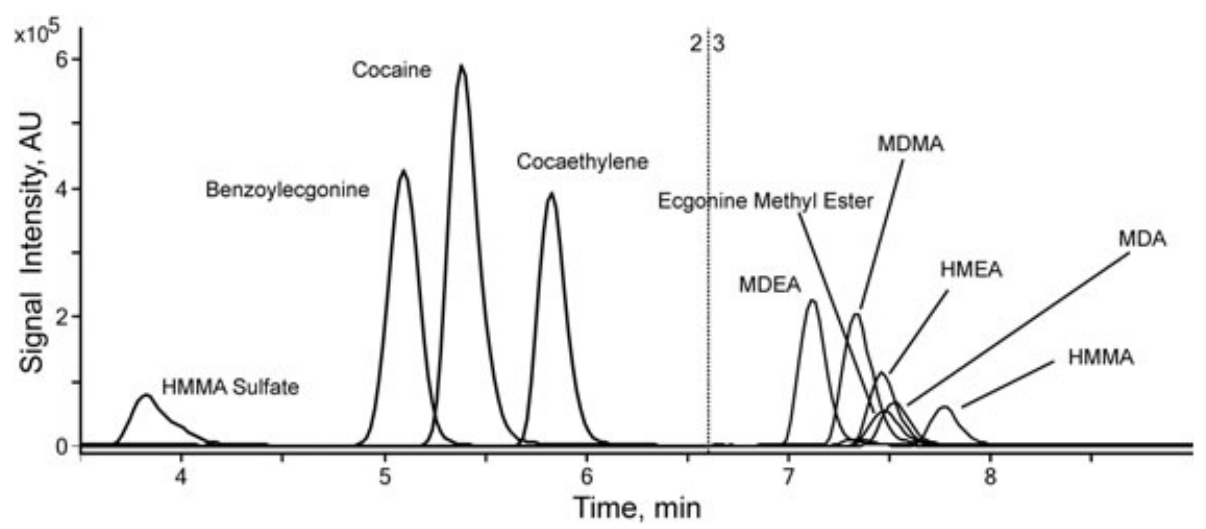

Figure 4. Reconstructed $\mathrm{m} / \mathrm{z}$ chromatograms for the quantifier transitions of BE and MDMA from medium level quality control sample, the rest from high level quality control sample. The line at $6.6 \mathrm{~min}$ indicates change in segments.

on concentration estimates from screening of PU and US. Concentrations of MDEA and HMEA were lower than the calibrated range for all incubations.

Sorption of $\mathrm{COC}, \mathrm{BE}$, and MDMA to solid particulate matter is less than $5 \%{ }^{[29]}$ Sorption was thus not investigated in the present study, as the more hydrophilic excretion products are expected to adsorb in the same order of magnitude or lower.

A variance analysis of three isolated steps was performed. Biological, sample preparation, and analytical variances from the study are summarized in Table 4. Generally, sample preparation and analytical variance were highest for the two analytes not having deuterated internal standards, i.e., HMMA-S and HMMA.

The confidence values of the stability after $24 \mathrm{~h}$ were higher than after $8 \mathrm{~h}$ for all investigated compounds. The most pronounced confidence values were from the MDMA metabolites. This variance is likely from the effect of having different absolute and relative levels of excretion products in the incubations.

Stability data after 8 and $24 \mathrm{~h}$ are shown in Table 4 and calculated as the percentage remaining relative to the concentration at $t 0$. Variance is given as confidence value at confidence level 0.05 , when $n>3$. Figure 5 shows stability curves over $24 \mathrm{~h}$ for the investigated metabolites as average of start concentration in percentage. After $8 \mathrm{~h}$ of incubation, COC and EME showed a medium stability, whereas BE and CE had a high stability. After $24 \mathrm{~h}$ COC and EME only had one sample in the calibrated range, respectively; BE and CE had a medium stability after $24 \mathrm{~h}$.

Previous stability studies found spiked BE to be stable over $24 \mathrm{~h}$, and spiked EME and COC over $8 \mathrm{~h} \cdot{ }^{[5,11]}$ Another study found spiked $\mathrm{COC}$ to be stable for $24 \mathrm{~h} \cdot{ }^{[12]}$ Spiked CE was found to be stable for $24 h,{ }^{[12]}$ which is in contrast to the findings of the current study. Different experimental conditions of the stability studies might explain such findings. However, overall findings in the present study were in line with previous findings for investigated COC excretion products. $^{[5,11,12]}$

Spiked MDMA has a high stability in wastewater ${ }^{[5,11,12]}$; this was also observed in the present study using urine. Urinary MDA has a marked increase in variation and it should be noted MDA was only within the calibrated range in four of the eight incubations. MDA is one of the compounds where the developed method performs best, based on low variances and high precision and accuracy from the method validation. An F-test comparing normalized biological variance $(n=3)$ for MDA after $24 \mathrm{~h}$ with sample preparation variance $(n=5)$ shows that the biological and sample preparation variance are unequal $\left(\alpha=0.05, \delta_{\text {MDA,Biovar t } 24 \mathrm{~h}} \neq \delta_{\text {MDA,SPVar, }} \mathrm{F}=17.1\right.$, $p=0.006)$. An F-test comparing the normalized variance from the incubations $(n=4)$ for MDA after $24 \mathrm{~h}$ to the biological variance $(n=3)$ after $24 \mathrm{~h}$ shows the incubation variance to be unequal to the biological variance $\left(\alpha=0.05, \delta_{\text {MDA,IncVar, } 24 \mathrm{~h}} \neq \delta_{\text {MDA,BioVar t24h }}\right.$

Table 4. Incubation data: Incubation range in $\mathrm{ng} / \mathrm{mL}$. Stability in average of $\mathrm{n}$ samples and the given time point expressed in a percentage of the original concentration remaining, confidence interval at $\alpha=0.05$. Variance data as standard deviation on normalized data $(\mu=1)$. Biological Variance from IncA, Sample preparation variance and analytical variance from IncC for MDMA excretion products, and IncG for COC excretion products. NA=not available

\begin{tabular}{|c|c|c|c|c|c|c|c|c|c|c|c|c|c|c|}
\hline & \multicolumn{2}{|c|}{ Incubation Range } & \multicolumn{6}{|c|}{ Stability } & \multicolumn{6}{|c|}{ Variance } \\
\hline & \multirow[b]{2}{*}{ Min } & \multirow[b]{2}{*}{ Max } & \multicolumn{2}{|c|}{$8 \mathrm{~h}$} & \multicolumn{3}{|c|}{$24 \mathrm{~h}$} & \multirow[b]{2}{*}{$\mathrm{n}$} & \multicolumn{4}{|c|}{ Biological variance } & \multirow{2}{*}{$\begin{array}{c}\text { Sample } \\
\text { prep variance } \\
(n=5)\end{array}$} & \multirow{2}{*}{$\begin{array}{c}\text { Analytical } \\
\text { variance } \\
(n=5)\end{array}$} \\
\hline & & & Average, $\%$ & CV & $\mathrm{n}$ & Average, $\%$ & CV & & Variance & $\begin{array}{c}3 \mathrm{~h} \\
(\mathrm{n}=3)\end{array}$ & $\begin{array}{c}12 \mathrm{~h} \\
(\mathrm{n}=3)\end{array}$ & $\begin{array}{c}24 \mathrm{~h} \\
(\mathrm{n}=3)\end{array}$ & & \\
\hline HMMA-S & $<$ LLOQ & 177.8 & 99 & 14 & 6 & 84 & 17 & 6 & 0.259 & 0.070 & 0.029 & 0.029 & 0.100 & 0.084 \\
\hline $\mathrm{BE}$ & 10.2 & 730.7 & 88 & 5 & 8 & 78 & 8 & 8 & 0.142 & NA & NA & 0.014 & 0.066 & 0.020 \\
\hline $\operatorname{coc}$ & $<\mathrm{LLOQ}$ & 27.5 & 74 & NA & 2 & 19 & NA & 1 & NA & NA & NA & NA & 0.026 & 0.029 \\
\hline CE & $<$ LLOQ & 57.0 & 88 & 3 & 4 & 56 & 12 & 4 & 0.083 & NA & NA & NA & 0.048 & 0.076 \\
\hline EME & $<\mathrm{LLOQ}$ & 18.7 & 67 & 12 & 3 & 46 & NA & 1 & NA & NA & NA & NA & 0.022 & 0.024 \\
\hline HMMA & $<\mathrm{LLOQ}$ & 102.3 & 102 & 17 & 7 & 107 & 27 & 7 & 0.339 & 0.027 & 0.025 & 0.123 & 0.061 & 0.091 \\
\hline MDA & $<\mathrm{LLOQ}$ & 35.2 & 85 & 10 & 4 & 103 & 46 & 4 & 0.454 & 0.084 & 0.035 & 0.062 & 0.007 & 0.032 \\
\hline MDMA & $<\mathrm{LLOQ}$ & 433.5 & 96 & 2 & 7 & 85 & 4 & 7 & 0.075 & 0.067 & 0.024 & 0.029 & 0.027 & 0.012 \\
\hline
\end{tabular}




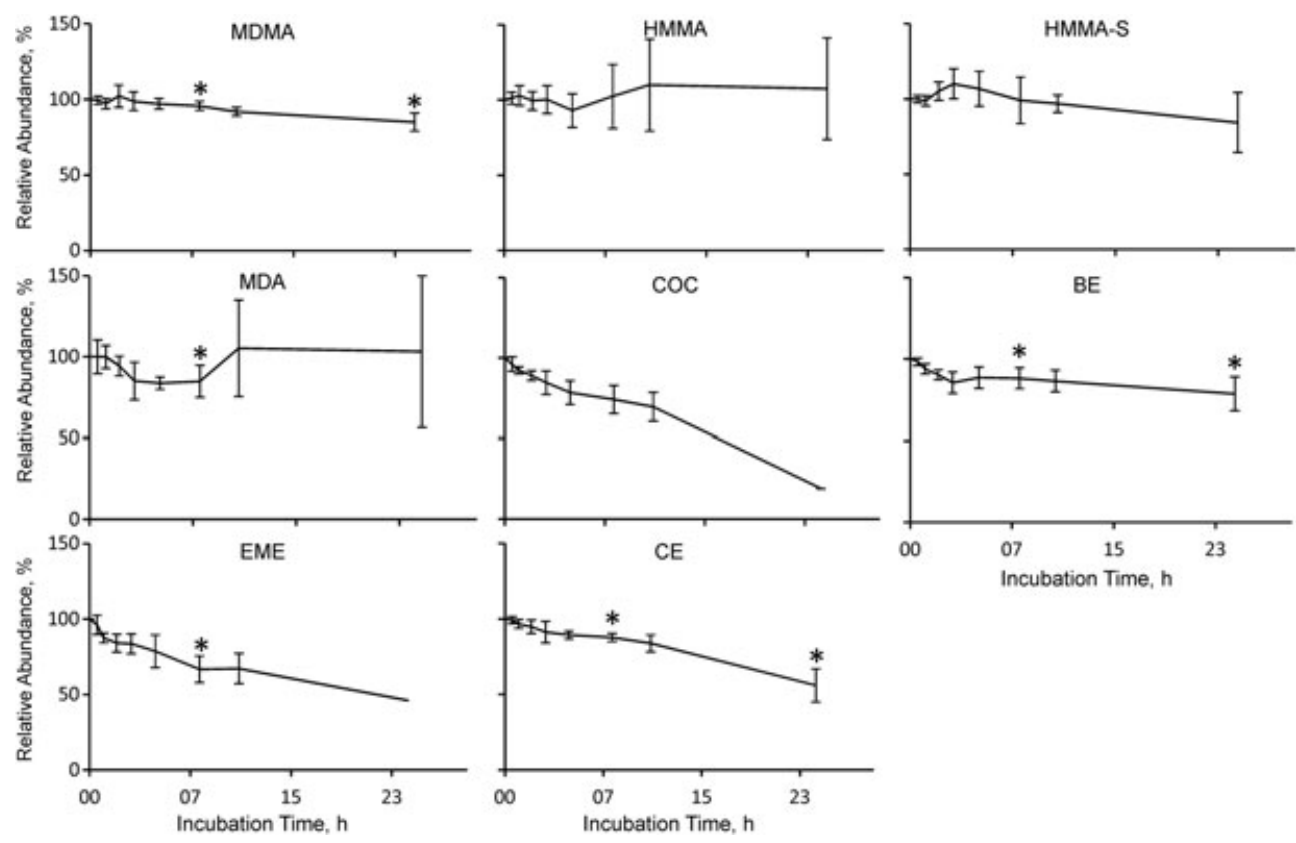

Figure 5. Stability curves showing normalized averages in a percentage of the original concentration remaining, against incubation time in $\mathrm{h}$. Error bars show confidence value (when $n>3, \alpha=0.05$ ). Stars indicate confidence intervals below $100 \%$, thus a significant decrease.

$F=168.9, p=0.006)$. The increased variation could be caused by different biotransformation pathways, such as $N$-demethylation of MDMA and O-demethylation to 3,4-dihydroxyamphetamine, as it was observed for MDPV. ${ }^{[4]}$ Previous studies have found spiked MDA to be stable in wastewater. ${ }^{[12]}$ Further studies should be encouraged for MDA to allow a better understanding of what happens with urinary MDA in wastewater, preferably using urine from MDA-only users.

Investigated MDMA excretion products have been shown to be stable for at least three freeze-thaw cycles in urine as well for six months at $-20^{\circ} \mathrm{C}^{[30]}$ However, conjugate cleaving during pre-concentration might have occurred in the present study. The average concentration of HMMA in the samples after $24 \mathrm{~h}$ was $107 \pm 27 \%(\alpha=0.05, n=7)$. The HMMA increase could be explained by cleaving of the corresponding phase II metabolites or by biotransformation of MDMA and 3,4dihydroxymethamphetamine into HMMA. The increase is however not significant due to the large variation. The pathway $O$-demethylenylation with subsequent $O$-methylation could also be a pathway relevant for MDMA, as it shares the methylenedioxy moiety with MDPV. ${ }^{[4]}$

HMMA-S showed a high stability and cleaving of the sulfate (and possibly glucuronide) would be of importance to use HMMA as a wastewater target for assessing consumption of MDMA. Stability of HMMA-S corresponds to findings by Gomes et al., who found conjugated estrogen sulfates to have a high stability for $8 \mathrm{~h}$ of incubation in wastewater. ${ }^{[14]}$ In contrast, estrogen glucuronides incubated in wastewater were completely deconjugated after $8 \mathrm{~h}$ of incubation in wastewater at $17^{\circ} \mathrm{C}$; furthermore, the opioid metabolite, morphine-3-glucuronide, has been shown to be unstable in wastewater after $24 \mathrm{~h} .{ }^{[12,13]}$ HMMA conjugate cleavage might be based on acidic hydrolysis, as previous studies have shown urinary HMMA concentrations to increase more than 30-fold after acidic hydrolysis of $1 \mathrm{~mL}$ urine at $160^{\circ} \mathrm{C}$ for $20 \mathrm{~min} \cdot{ }^{[31]}$ As wastewater analysis requires volumes in the range $50-100 \mathrm{~mL}$ per sample, acidic hydrolysis under elevated temperatures should be worth investigating in the future.

\section{Conclusions}

Screening of pooled urine and urinated soil samples showed COC and MDMA to be the main consumed illicit drugs in the contributing festival population. A HILIC-MS/MS method was developed and validated to assess the stability of COC, MDMA, and MDEA excretion products. Assessing the stability of targets for illicit drug consumption with urinary excretion products should give a better understanding on how transformations in the sewer system affects concentrations of investigated targets. For the first time, HMMA and HMMA-S were both shown to be stable in wastewater after 8 and $24 \mathrm{~h}$ of incubation. HMMA should thus be a suitable biomarker to monitor MDMA consumption in WBE studies. Further studies should investigate conjugate cleavage of HMMA-S and glucuronide and the detectability of HMMA in real wastewater samples.

\section{Acknowledgements}

The authors would like to thank Prof. Hans H. Maurer, Armin A. Weber, Walid Maho, Benedek Plósz, Kristof Maudens, Inger Boeg Sundby Nielsen, Lena Arndal, Henrik Larsen, and lab technicians for their support. This study received funding from the European Union's Seventh Framework Programme for research, technological development, and demonstration under grant agreement No. 317205.

\section{References}

[1] S. Castiglioni, K. V. Thomas, B. Kasprzyk-Hordern, L. Vandam, P. Griffiths. Testing wastewater to detect illicit drugs: state of the art, potential and research needs. Sci. Total Environ. 2014, 487, 613.

[2] E. Zuccato, C. Chiabrando, S. Castiglioni, R. Bagnati, R. Fanelli. Estimating community drug abuse by wastewater analysis. Environ. Health Perspect. 2008, 116, 1027.

[3] S. Salvatore, J. G. Bramness, M. J. Reid, K. V. Thomas, C. Harman, J. Roislien. Wastewater-Based Epidemiology of Stimulant Drugs: Functional Data Analysis Compared to Traditional Statistical Methods. PLoS One. 2015, 10, e0138669. 
[4] M. Mardal, M. R. Meyer. Studies on the microbial biotransformation of the novel psychoactive substance methylenedioxypyrovalerone (MDPV) in wastewater by means of liquid chromatography-high resolution mass spectrometry/mass spectrometry. Sci. Total Environ. 2014, 493, 588.

[5] A. L. van Nuijs, K. Abdellati, L. Bervoets, R. Blust, P. G. Jorens, H. Neels, A. Covaci. The stability of illicit drugs and metabolites in wastewater, an important issue for sewage epidemiology? J. Hazard. Mater. 2012, 239-240, 19.

[6] M. R. Meyer, H. H. Maurer. Metabolism of designer drugs of abuse: an updated review. Curr. Drug Metab. 2010, 11, 468.

[7] J. R. Archer, P. I. Dargan, S. Hudson, D. M. Wood. Analysis of anonymous pooled urine from portable urinals in central London confirms the significant use of novel psychoactive substances. QJM. 2013, 106, 147.

[8] J. R. Archer, S. Hudson, D. M. Wood, P. I. Dargan. Analysis of urine from pooled urinals - a novel method for the detection of novel psychoactive substances. Curr. Drug Abuse Rev. 2013, 6, 86.

[9] J. R. Archer, S. Hudson, O. Jackson, T. Yamamoto, C. Lovett, H. M. Lee, S. Rao, L. Hunter, P. I. Dargan, D. M. Wood. Analysis of anonymized pooled urine in nine UK cities: variation in classical recreational drug, novel psychoactive substance and anabolic steroid use. QJM. 2015, $108,929$.

[10] J. R. Archer, P. I. Dargan, H. M. Lee, S. Hudson, D. M. Wood. Trend analysis of anonymised pooled urine from portable street urinals in central London identifies variation in the use of novel psychoactive substances. Clin. Toxicol. (Phila.). 2014, 52, 160.

[11] P. K. Thai, G. Jiang, W. Gernjak, Z. Yuan, F. Y. Lai, J. F. Mueller. Effects of sewer conditions on the degradation of selected illicit drug residues in wastewater. Water Res. 2014, 48, 538.

[12] D. R. Baker, B. Kasprzyk-Hordern. Critical evaluation of methodology commonly used in sample collection, storage and preparation for the analysis of pharmaceuticals and illicit drugs in surface water and wastewater by solid phase extraction and liquid chromatographymass spectrometry. J. Chromatogr. A. 2011, 1218, 8036.

[13] I. Senta, I. Krizman, M. Ahel, S. Terzic. Assessment of stability of drug biomarkers in municipal wastewater as a factor influencing the estimation of drug consumption using sewage epidemiology. Sci. Total Environ. 2014, 487, 659.

[14] R. L. Gomes, M. D. Scrimshaw, J. N. Lester. Fate of conjugated natural and synthetic steroid estrogens in crude sewage and activated sludge batch studies. Environ. Sci. Technol. 2009, 43, 3612.

[15] S. Castiglioni, L. Bijlsma, A. Covaci, E. Emke, F. Hernandez, M. Reid, C. Ort, K. V. Thomas, A. L. van Nuijs, P. de Voogt, E. Zuccato. Evaluation of uncertainties associated with the determination of community drug use through the measurement of sewage drug biomarkers. Environ. Sci. Technol. 2013, 47, 1452.

[16] A. E. Schwaninger, M. R. Meyer, A. J. Barnes, E. A. Kolbrich-Spargo, D. A. Gorelick, R. S. Goodwin, M. A. Huestis, H. H. Maurer. Urinary excretion kinetics of 3,4-methylenedioxymethamphetamine (MDMA, ecstasy) and its phase I and phase II metabolites in humans following controlled MDMA administration. Clin. Chem. 2011, 57, 1748.

[17] A. E. Schwaninger, M. R. Meyer, J. Zapp, H. H. Maurer. Sulfation of the 3,4-methylenedioxymethamphetamine (MDMA) metabolites 3,4dihydroxymethamphetamine (DHMA) and 4-hydroxy-3-methoxymetham phetamine (HMMA) and their capability to inhibit human sulfotransferases. Toxicol. Lett. 2011, 202, 120.
[18] H. K. Ensslin, H. H. Maurer, E. Gouzoulis, L. Hermle, K. A. Kovar. Metabolism of racemic 3,4-methylenedioxyethylamphetamine in humans. Isolation, identification, quantification, and synthesis of urinary metabolites. Drug Metab. Dispos. 1996, 24, 813.

[19] J. Welter, M. R. Meyer, P. Kavanagh, H. H. Maurer. Studies on the metabolism and the detectability of 4-methyl-amphetamine and its isomers 2-methyl-amphetamine and 3-methyl-amphetamine in rat urine using GC-MS and LC-(high-resolution)-MSn. Anal. Bioanal. Chem. 2014, 406, 1957.

[20] A. G. Helfer, J. A. Michely, A. A. Weber, M. R. Meyer, H. H. Maurer. Orbitrap technology for comprehensive metabolite-based liquid chromatographic-high resolution-tandem mass spectrometric urine drug screening - exemplified for cardiovascular drugs. Anal. Chim. Acta. 2015, 891, 221.

[21] D. K. Wissenbach, M. R. Meyer, D. Remane, A. A. Philipp, A. A. Weber, H. H. Maurer. Drugs of abuse screening in urine as part of a metabolite-based LC-MSn screening concept. Anal. Bioanal. Chem. 2011, 400, 3481.

[22] EMA. Vol. EMEA/CHMP/EWP/192217/2009 Rev.1 Corr. 2, 2015 ed. European Medicines Agency, 2011. http://www.ema.europa.eu/docs/en_GB/ document_library/Scientific_guideline/2011/08/WC500109686.pdf

[23] A. K. McCall, R. Bade, J. Kinyua, F. Y. Lai, P. K. Thai, A. Covaci, L. Bijlsma, A. L. N. van Nuijs, C. Ort. Critical review on the stability of illicit drugs in sewers and wastewater samples. Water Res. 2016, 88, 933.

[24] M. R. Meyer, F. T. Peters, H. H. Maurer. The role of human hepatic cytochrome P450 isozymes in the metabolism of racemic 3,4methylenedioxyethylamphetamine and its single enantiomers. Drug Metab. Dispos. 2009, 37, 1152.

[25] M. R. Meyer, F. T. Peters, H. H. Maurer. The role of human hepatic cytochrome P450 isozymes in the metabolism of racemic 3,4methylenedioxy-methamphetamine and its enantiomers. Drug Metab. Dispos. 2008, 36, 2345.

[26] M. S. Castaneto, A. Wohlfarth, N. A. Desrosiers, R. L. Hartman, D. A. Gorelick, M. A. Huestis. Synthetic cannabinoids pharmacokinetics and detection methods in biological matrices. Drug Metab. Rev. 2015, 47, 124.

[27] K. L. Thoren, J. M. Colby, S. B. Shugarts, A. H. Wu, K. L. Lynch. Comparison of Information-Dependent Acquisition on a Tandem Quadrupole TOF vs a Triple Quadrupole Linear Ion Trap Mass Spectrometer for BroadSpectrum Drug Screening. Clin. Chem. 2016, 62, 170.

[28] J. Kinyua, A. Covaci, W. Maho, A. K. McCall, H. Neels, A. L. van Nuijs. Sewage-based epidemiology in monitoring the use of new psychoactive substances: Validation and application of an analytical method using LC-MS/MS. Drug Test. Anal. 2015, 7, 812.

[29] D. R. Baker, B. Kasprzyk-Hordern. Multi-residue determination of the sorption of illicit drugs and pharmaceuticals to wastewater suspended particulate matter using pressurised liquid extraction, solid phase extraction and liquid chromatography coupled with tandem mass spectrometry. J. Chromatogr. A. 2011, 1218, 7901.

[30] A. E. Schwaninger, M. R. Meyer, M. A. Huestis, H. H. Maurer. Development and validation of LC-HRMS and GC-NICl-MS methods for stereoselective determination of MDMA and its phase I and II metabolites in human urine. J. Mass Spectrom. 2011, 46, 603.

[31] S. O. Pirnay, T. T. Abraham, R. H. Lowe, M. A. Huestis. Selection and optimization of hydrolysis conditions for the quantification of urinary metabolites of MDMA. J. Anal. Toxicol. 2006, 30, 563. 